\title{
Impact of Internet Advertisement and Its Features on E-Commerce Retail Sales: Evidence from Europe
}

\author{
Osama Harfoushi ${ }^{1}$, Bader Alfawwaz ${ }^{2}$, Bader Obeidat $^{3}$, Ruba Obiedat ${ }^{1}$, Hossam Faris $^{1}$ \\ ${ }^{1}$ Department of Business Information Technology, The University of Jordan, Amman, Jordan; ${ }^{2}$ Department of Computer Information \\ System, Al-albayt University, Mafraq, Jordan; ${ }^{3}$ Department of Business Administration, The University of Jordan, Amman, Jordan. \\ Email: o.harfoushi@ju.edu.jo,bm_alfawwaz@aabu.edu.jo,b.obeidat@ju.edu.jo,r.obiedat@ju.edu.jo, hossam.faris@ju.edu.jo
}

Received September $4^{\text {th }}, 2013$; revised October $1^{\text {st }}, 2013$; accepted October $10^{\text {th }}, 2013$

Copyright (C) 2013 Osama Harfoushi et al. This is an open access article distributed under the Creative Commons Attribution License, which permits unrestricted use, distribution, and reproduction in any medium, provided the original work is properly cited.

\begin{abstract}
The stimulus to carry out this research is to investigate the relationship between internet advertisement and its features on the total E-commerce sales of the top five countries of Europe. The units of analysis are the individuals of UK, France, Italy, Germany and Netherland. Secondary data are collected from the reports of [1] (ADEX, 2010) and [2] (Eurostats, 2011). To empirically determine the relationship between independent variable and dependent variable in the European context, the study uses various statistical techniques, including OLS regression and correlation analysis techniques. The empirical findings indicate that the Internet advertisement features of search advertisement and classified advertisement have positive significant relationship with the E-commerce sales in Europe. The empirical findings indicate negative significant relationship of display advertisement with the E-commerce sales in Europe. However, this variable is also justified with the help of literature. Findings also demonstrate that search advertisement has strong positive relationship and it generates positive influence for the E-commerce sales as compared to the classified advertisement and display advertisement. Firms and marketers which are investing in online advertisement will find these results useful as they can get better sales and can use these features of online advertisement in order to maximize the sales of their products and services.
\end{abstract}

Keywords: Features of Internet Advertisement; Display Advertisement; Search Advertisement; Classified Advertisement; E-Commerce Sales; E-Commerce Sale in Europe

\section{Introduction}

Internet is becoming a new way to shop different products or services online. Although, it is a desire situation for everyone to touch the products that he/she wants to buy. However, Internet is playing a wider role in making the shopping more easily as it is never before. The web makes shopping much easier, and nowadays shopping is not more than away from a click. A latest term is introduced that is known as "Online Shopping". Consumers can directly shop product or services from the sellers without any interaction of intermediate parties. There are over 875 million consumers who have shopped online. The number of Internet shoppers has increased by $40 \%$ in two years [2] (Eurostats, 2011). These are the trends in online shopping and these trends are increasing worldwide. Besides buying products online, the ability to get the services through a simple click makes it easier and more comfortable. For instance, booking travel tickets, getting concert or matches tickets and online banking are some of the services which consumers love to get conveniently through Internet. When a consumer buys from a business, it is called $\mathrm{B} 2 \mathrm{C}$; and, when business buys from another business, it is known as B2B.

Just like other direct marketing channels such as television and catalogs, Internet is also becoming a significant marketing channel. The Internet supports two-way communications between consumer and merchant. The web provides interactive shopping channel, which is not bounded by time and geographical condition. Moreover, it supports a variety of alternatives to approach extensive retailing activities over Internet. Like marketing the products in traditional market, similar in the context of Internet, products or services are also use to be marketed. Many modern merchants and organizations have developed their pages to promote or market their products and services over worldwide Web. 
In European countries, the Internet market is at developed stage, although in European countries many people avoid shopping from an E-store. Lack of trust is one of the most frequently cited reasons for consumers not to purchase from the Internet [3] (Turban, 2011). The users of Internet in Europe have been recorded 105,096,093 [4] (Stats, 2011). The number of Internet users is increasing rapidly in Europe and around the globe. Beside that the number of internet users in Europe is increasing, similarly, the number of Internet shoppers is also increasing. $80 \%$ of the Internet users in Europe have bought or ordered goods or services for private use over the Internet [2] (Eurostats, 2011). Basically, there are certain factors which are encouraging Internet shopping, such as secure payments, accessibility and demonstration of Retailers or merchants and physical existence of the products [5] (Todd, 1997).

When talking about Internet advertisement, few things have been observed on the Internet world. Due to the low cost, high speed on Internet, and accessibility to different products, Internet is becoming a most acceptable platform for the shopping purpose. Internet is becoming a novel platform for attracting consumer's attention by the online advertisement [6] (Rowley, 2001). It has been observed that companies are spending huge amount of money for advertisement on interactive media. According to the Euro stats, the database of statistics, Euro.21 billion has been spending on the Internet advertisement from the FY 2010 to FY 2011 [7] (Eurostats, 2011). As companies are spending huge amount of money, it is significant to measure whether this huge amount of money generates desirable outcomes or not. Moreover, there might be huge potential in online advertisement as the stats indicates that Internet users increase from $16 \%$ to $65.7 \%$ from 2000 to 2008 around the globe [8] (Internet world stats, 2008). If we talk specifically about Europe, then according to the stats of world bank, Internet users being recorded are $61.3 \%$ of the total population of entire Europe [9] (World Bank, 2010). The exact figure recorded by the Internet world stats of Internet users in Europe as by 2011 is 1.5 billion (Statistics, 2011). The stats indicates that companies need to emphasize on online advertisement in Europe more and more as there is huge potential in the European online market.

\section{Literature Review}

Literature review is based on overview of Internet advertisement, and overview of features of online advertisement which put impact on the consumer purchase intensions.

\subsection{Overview of Internet Advertisement}

Advertising is defined as "any paid form of non-personal communication of ideas and information about products in the media with the objective of creating brand image [10] (Armstrong, 2010). Long time ago the marketing on Television and Print media was the major source of advertisement, but in today's world Internet marketing has become another major source of online advertisement. Internet is flattering powerful force in many promotion initiatives and efforts [10] (Armstrong, 2010). To cover up this platform of advertising companies are planning for the growth of online retailing, but for this purpose they are definitely in need of correct estimates of online purchasing behaviors [11] (Gerald Lohse, 2000). "In the Internet environment, consumers do not need to conform to the expectations of others when making a purchase, and they all have informational influence that enables them to make good decisions. Internet Advertisement is becoming a significant tool that is used to market the products and services by the industrial and non-industrial organizations [12] (RAVIKUMAR, 2012). Furthermore studies indicate that electronic business also come up with the new forms of advertisement such as banners, pop ups, videos, content and other advertisement links [13] (Manchanda, 2006).

According to an estimate the total expenditure of online advertisement is around $\$ 66.6$ billion in all over the world [14] (The Wall Street Journal, 2004). Due to this fact companies which are planning to enhance their online operations on the Internet platform they are looking for the exact measures and estimates which can tell them that whether there is consumer response or not. Those companies which are strategizing for the growth of retailing on Internet they are certainly in need of reliable estimates for the growth of Internet shopping [15] (Lohse, 2000). Without any doubt significant increase has been observed in the internet advertisement sector. It is proven to become another platform which is drawing the attention of companies towards itself. It is commonly observed that companies are allocating a significant amount for the purpose of online advertisement. Internet advertising stats swathe areas that narrate to publicity brands over the internet and comprise banner advertising, advertising performance, search engine advertising/PPC advertising, and further development and stats associated to internet advertising. According to [16] (Grabstats, 2008) revenue of internet advertisement has $38 \%$ growth from 2000-2008. Internet advertisement is effectual if it is talented to produce an instant retort from the customers [17] (Tse, 2005). More importantly three features are used in internet advertisements which are Multimedia feature, Pictures and content features. These features have been used by the model proposed by [18] (Rutgars, 2003).

\subsection{Features of Online Advertisemen}

Display is a form of expression which includes Anima- 
tion, Videos and moving pictures [19] (Rosenkrans, 2007). The display feature includes many technologies such as flash, Java ads, pop ads and moving images [20] (Yoo, 2004). Furthermore consumer has better perception and positive buying behavior when they see the moving advertisement, colored ads, Java ads or videos on any E-commerce website [17] (Tse, 2005). This is why companies are focusing on the development of digital advertisements on the interactive media to grab the attention of more and more customers. Companies that construct thematic associations flanked by the game and the product's make would summon an encouraging persuade on consumer approach toward that particular brand or make [21] (Wise, 2008).

Another major internet advertisement features are the search and classified advertisement. Without any doubt search and classified advertisement become more attractive and appealing for the customers who are looking for online shopping purpose [22] (Loiacono, 2008). Further a study indicate that search and classified advertisement are the most ideal and put efficient influence on the consumer perception for the particular products are services on the Internet as compared to the content advertisements [23] (Kumar, 2008). Search and classified advertisement are working as an effective tool in drawing the viewer attention towards itself. However, there are certain drawbacks of this online advertisement feature. The main drawback of this feature is this that it takes some time in order to download the picture and appear on to the viewer's screen. A study finding shows that normally a consumer wait for 15 seconds for any picture to download so that he/she can view it (Adam, 2003). So it appears that if a picture or image would not be downloading before 15 seconds then consumer will switch towards any other website or E-store for the shopping purpose.

\subsection{E-Commerce Retail Saleson Internet}

It is significantly important to study the total E-commerce sales patterns and trends in the specific area. Several studies [24] (Häubl, 2000), [25] (Andrews, 2000), [26] (Bakos, 2000), have conducted empirical research about consumer purchase or in other words saleson the internet. These studies were basically trying to figure out the difference between traditional and online environment. Literature shows a strong relationship between the internet advertisement and E-commerce retails sales on the Internet. Findings show that if the internet advertisement has increased the E-commerce sales are also increased. Finding of a study indicates "Consumers who felt that Web sites improved their perceptions of brands saw more advantages in Web advertising and they intend to purchase from that website" [27] (Ronald and Barbara, 2002) Most of the studies were on the price and brand choice in an online environment and results indicated that there is a blend of evidence for the role of information in the virtual environment.

Andrews (2000) [25] finds that "the brand loyalty coefficient in a multinomial logic model is lower for online versus offline grocery shopping, but online shoppers select from a smaller consideration set of brands, thereby remaining loyal to a smaller number of brands".

This is the research gap in literature and to fulfill this gap we have conducted the similar study by using the secondary data of European countries.

\section{Theoretical Framework}

The theoretical framework of "impact of Internet Advertisement and its features on E-commerce Retail Sales: Evidence from Europe"

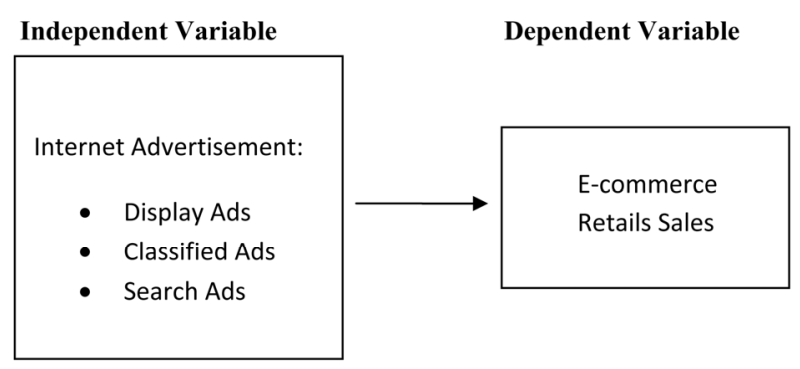

Source: Adapted from [37] (Wei et al., 2010).

\section{Hypothesis}

H1: Classified Advertisement has positive relationship with the E-commerce sales in European countries.

H2: Display Advertisement has positive relationship with the E-commerce Sales in European countries.

H3: Search Advertisement has positive relationship with the E-commerce Sales in European countries.

\section{Research Methodology}

This section of the study will discuss the research methodology use to find out the relationship between independent variables and dependent variables. The methodology of this study will be quantitative and based on secondary data collection. Cross sectional data of different countries of Europe has been collected. Countries are: United Kingdom (UK), Germany, France, Netherland and Italy. Ten years data has been collected from 2001 to 2010. These countries are from the Europe zone and these countries are among the top five countries among other countries of Europe in usage of Internet, spending on Internet Advertisement and purchasing or sales from the Internet by the consumers. The data for all three independent variables which are Display Ads, Classified Ads and Search Ads are collected from the reports of IAB ADEX [28] (ADEX, 2001), [29] (ADEX, 2002), [30] 
(ADEX, 2003), [31] (ADEX, 2004), [32] (ADEX, 2005), [33] (ADEX, 2006), [34] (ADEX, 2007), [35] (ADEX, 2008), [36] (ADEX, 2009) and [1] (ADEX, 2010). The data of dependent variable is collected from a report or a book. The report is [37] (Jeffrey, 2010) and the book is [38] (Zenithoptimedia, 2011). An Email was sent to Zenithoptimedia team to provide this book in order to collect the right data. No other agency or publisher, or any other journal is offering such report; even Gallup is not recording the Internet Advertisement data so data was collected by personal efforts. Total 50 observations have been recorded as five European countries have been chosen and their ten years of data has been collected.

The data is analyzed by using E-views 5 . All the data was first recorder in MS-Excel then arrange the data in E-view and apply different tests. Descriptive test has been applied for the analysis of properties of data. Descriptive analysis consists of Mean, Median, Standard Deviation, Skewness, Kurtosis and number of observations as well. In addition with descriptive test, correlation matrix is also generated which tells us the extent of relationship between the independent variables and the dependent variables. This correlation matrix is good in order to check the variables relationship between independent and independent variables and independent to dependent variables. Furthermore, Ordinary Least Square (OLS) regression test is also applied to estimates the desirable results. It shows us the dependence of dependent variables to independent variables. $\mathrm{R}$ square and Adjusted R square is also estimated which tells us the effect of multicollinearity between the independent variables. Also Durbin test results calculated which tells us the problem of Autocorrelation in the results. This OLS regression is used because it is important to check the dependency of the variables to each other. Moreover, it is also important to check whether there is effect of multicollinearity or not? Also it tells the problem of Autocorrelation which is also important to check in the data.

General model equation of the study which is statistically estimated to signify the relationship is as under.

$$
\begin{aligned}
\text { ESALE } & =\beta 0+\beta 1 \text { CLASS it } \\
& +\beta 2 \text { SEARCH it }+\beta 3 \text { DISPLAY it }+\mu \text { it }
\end{aligned}
$$

where:

ESALE $=$ Total E-commerce Sales

CLASS $=$ Classified Advertisement

SEARCH $=$ Search Advertisement

DESPLAY $=$ Display Advertisement

\section{Results \& Discussions}

This section presents the empirical findings regarding the relationship that exists among variables selected for the study. First of all it presents the descriptive or summary statistics, which shows the properties of the data. This section also presents the OLS regression results and correlation Matrix results, as well as theoretical discussion on results of these models. Interpretation of each result will be done in this section.

Table 1 depicts the descriptive statistics for the independent and dependent variables which are considered. As the sample of the study includes the 05 countries and the data period covered for ten years ranging from 2001-2010, so the total number of observations become fifty. The sample of the study reveals that average of classified Advertisement is 250.44; the mean of Display Advertisement is 344.36 . Similarly the average of search advertisement is 555.12 and the average of dependent variable which is E-commerce Sales is 20.66. Further the standard deviation of classified Advertisement is 271.15; the standard deviation of Display Advertisement is 317.29. Similarly the standard deviation of search advertisement is 665.54 and the standard deviation of dependent variable which is E-commerce Sales is 19.02. In addition to Mean and Standard Deviation other descriptive results are also given which are median, skenewss, kurtosis and probability of each variable.

Table 2 depicts the correlation Matrix in which correlation results of each variable is given. As there are three independent variables i.e. Classified Advertisement, Display Advertisement, Search Advertisement and one dependent variable i.e. E-commerce Sales, so correlation results with respect to each variable is given. Correlation tells us the extent of relationship between two variables. Correlation result between the variable itself such as Display Ad of Display Ad is strongly significant or 1 and vice versa. Correlation results between Classified and Display Advertisement is 0.83 which shows strong rela-

Table 1. Descriptive statistics.

\begin{tabular}{ccccc}
\hline & CLASSIFIED & DISPLY & ECOMSALE & SEARCH \\
\hline Mean & 250.4400 & 344.3600 & 20.66200 & 555.1200 \\
Median & 153.0000 & 232.0000 & 15.85000 & 302.0000 \\
Maximum & 874.0000 & 1272.000 & 83.50000 & 2731.000 \\
Minimum & 5.000000 & 7.000000 & 0.800000 & 16.00000 \\
Std. Dev. & 271.1560 & 317.2999 & 19.02158 & 665.5494 \\
Skewness & 0.990382 & 1.065653 & 1.513656 & 1.615724 \\
Kurtosis & 2.415678 & 3.432945 & 4.853007 & 4.860979 \\
Jarque-Bera & 8.885124 & 9.853965 & 26.24635 & 28.96978 \\
Probability & 0.011766 & 0.007248 & 0.000002 & 0.000001 \\
Sum & 12522.00 & 17218.00 & 1033.100 & 27756.00 \\
Sum Sq. Dev. & 3602754. & 4933282. & 17729.20 & 21704847 \\
Observations & 50 & 50 & 50 & 50 \\
\hline
\end{tabular}


Table 2. Correlation matrix.

\begin{tabular}{ccccc}
\hline & CLASSIFIED & DISPLY & ECOMSALE & SEARCH \\
\hline CLASSIFIED & 1 & 0.830893671771689 & 0.869408346196187 & 0.818317189838863 \\
DISPLY & 0.830893671771689 & 1 & 0.831313355900985 & 0.792074170206665 \\
ECOMSALE & 0.869408346196187 & 0.831313355900985 & 1 & 0.959616746708359 \\
SEARCH & 0.818317189838863 & 0.792074170206665 & 0.959616746708359 & 1 \\
\hline
\end{tabular}

tionship. Similarly, correlation results between classified and E-commerce sales are 0.86 which also shows strong relationship. Correlation results between Classified and Search Advertisement is 0.81 which is strong relationship. Correlation results between Display and E-commerce sales are 0.83 which is a strong relationship. Correlation results between Display and Search is 0.79 which is also strong relationship. Correlation results between E-commerce Sales and Search is 0.95 which also shows strong relationship with each other. Correlation results between Search and Classified Advertisement is 0.81 which is a strong relationship.

Table 3 depicts the random effect model estimated through OLS (Ordinary Least Square) regression. The Search Advertisement value of probability is 0.000 which shows it has very high or strong significant impact on the dependent variable which is E-commerce sales. Similarly the P-value of Classified Advertisement is 0.005 which also shows it has a significant impact on the E-commerce Sales. Whereas, results indicate that the Pvalue of Display Advertisement is 0.1791, which is greater the confidence of interval so it has weak impact on E-commerce Sales. Although it has some impact of E-commerce sales but that impact is low. T-stats of classified advertisement is 2.88 which is more than 2 so it shows significant positive impact of Classified Ad on dependent variable which is E-commerce Sales. Same in the case of Search Advertisement, the T-stats is 11.16 which is also more than 2 and it shows a significant positive impact on E-commerce sales. But when we see the results of Display advertisement the T-stats is 1.36 which is less than 2 so it shows negative impact on the dependent variable which is E-commerce Sales. The value of $\mathrm{R}$ square is 0.944 which is more than 0.90 which shows that there is the effect of multicollinearity between the independent variables. By seeing the Adjusted R square which is basically for more than two independent variables shows that there is multicollinearity effect between classified Ads, Search Ads and Display Ads. The Durbin Watson result should be more than 1.96 only than there will be no problem of autocorrelation, so when we see the results of Durbin Watson test in Table 3, its value is 1.057 which is less than 1.96 and it means there is no problem of autocorrelation. Overall the random effect model best explain the association among variable.
Table 3. Ordinary lease square regression statistics.

Dependent Variable: ECOMSALE

Method: Panel Least Squares

Date: 07/08/12 Time: 05:41

Sample: 20012010

Cross-sections included: 5

Total panel (balanced) observations: 50

Variable Coefficient Std. Error t-Statistic Prob.

$\begin{array}{lllll}\text { C } & 3.765645 & 0.971634 & 3.875580 & 0.0003\end{array}$

$\begin{array}{lllll}\text { CLASSIFIED } & 0.014339 & 0.004964 & 2.888314^{*} & 0.0059\end{array}$

$\begin{array}{lllll}\text { DISPLY } & 0.005450 & 0.003995 & 1.364391 & 0.1791\end{array}$

$\begin{array}{lllll}\text { SEARCH } & 0.020588 & 0.001844 & 11.16664^{*} & 0.0000\end{array}$

R-squared $\quad 0.944537$ Mean dependent var 20.66200

$\begin{array}{llll}\text { Adjusted R-squared } & 0.940920 & \text { S.D. dependent var } \quad 19.02158\end{array}$

S.E. of regression 4.623442 Akaike info criterion 5.976774

Sum squared resid $\quad 983.3060 \quad$ Schwarz criterion $\quad 6.129736$

Log likelihood $\quad-145.4194 \quad$ F-statistic $\quad 261.1296$

Durbin-Watson stat $1.057464 \quad$ Prob(F-statistic) $\quad 0.000000$

Note: Shows significance at $1 \%$ level of significance.

\section{Discussion on Hypothesis Testing}

This section presents the discussion on each hypothesis which we propose on the basis of substantive literature. Empirical reflection on each hypothesis will be analyzed to decide whether hypothesis projected have a significant or insignificant relationship. As the results of T-stats and $\mathrm{P}$-value of classified Advertisement is good and shows significant relationship with the E-commerce sales so on the basis of that we accept the H1. When we talk about $\mathrm{H} 2$, the P-value and T-statistics is not substantial and not showing significant relationship with the dependent variable which is E-commerce sales but in theory it has positive significant relationship with the E-commerce sales. Findings of a study says "The results of an experiment indicate that if a display ad is placed on a website then the ad should be highly congruent with the site than it will bring effective results for the advertiser" [39] (Eric, 
2004). Moreover another finding which is particularly about effect of banner advertisement on the consumer purchase intension, they also proved that display or image advertisement has strong positive impact on consumer buying or purchases on Internet. Purchases ultimately mean the sales on Internet [40] (Ronald, 2002). So in the light of these results in literature we might accept the H2 and accept the statement that Display Ads has strong significant positive relationship with the total E-commerce sales. In addition to $\mathrm{H} 1$ results, when we see the t-stats and p-value of $\mathrm{H} 3$ it also shows positive significant relationship with the E-commerce sales by these values we accept the $\mathrm{H} 3$.

\section{Conclusion and Recommendations}

The aim of this research stream was to empirically determine the impact of Internet advertisement and its features on E-commerce sales. The empirical seating of the study is provided by the Internet retail sales of Europe. The determinants or the dimensions of independent variable are further divided into three categories: The Display Advertisement, The Classified Advertisement and The Search Advertisement. The empirical finding of the study suggests that Internet advertisement is significantly associated with the E-commerce sales in the European countries. Empirical findings are: 1) the independent variables which are classified advertisement and the search advertisement have positive relationship with the E-commerce sales; and 2) independent variable which is display advertisement has negative relationship with the E-commerce sales. This study does not find any relationship between display advertisement and the E-commerce purchases/sales. However, with the help of literature [39] (Eric, 2004) and [40] (Ronald, 2002), these studies show that banner advertisement or display advertisement has positive relationship with the E-commerce purchases/ sales in the European context. Overall, the results of the study are best aligned with the previous studies expounded in the literature [39] (Eric, 2004), [11] (Gerald Lohse, 2000) and [41] (Wei et al., 2010). This research stream will hopefully contribute to the recent literature on the determinations of Internet advertisement and their effect on total E-commerce sales in European countries. In summary, this research study is related to the sales done by the consumers or individuals in Europe.

\section{REFERENCES}

[1] ADEX, "European Online Advertising Expenditure," IAB Europe, Belgium, 2010.

[2] H. Seybert, "Internet Use in Households and by Individuals in 2011," Eurostat Statistics in Focus, Vol. 66, 2011 http://www.ec.europa.eu/eurostat

[3] M. K. Turban, "A Trust Model for Consumer Internet Shop- ping," International Journal of Electronic Commerce, Vol. 6, No. 1, 2011, pp. 75-91.

[4] I. W. Stats, "Internet World Stats," Internet World Stats, 2012. http://www.internetworldstats.com/asia/pk.htm

[5] S. L. Todd, "Consumer Reactions to Electronic Shopping on the World Wide Web," International Journal of Electronic Commerce, Vol. 1, No. 2, 1997, pp. 59-88.

[6] Rowley, "Remodeling Marketing Communications in an Internet Environment, Internet Research," Electronic Networking Applications and Policy, Vol. 11, No. 3, 2001, pp. 203-212.

http://dx.doi.org/10.1108/10662240110397017

[7] Eurostats, "Online ad spend across Europe," 2011. http://www.ec.europa.eu/eurostat

[8] Internet World Stats, "Internet Usage Statistics and Marketing Report," Internet World Stats, 2012. http://www.internetworldstats.com/asia/my

[9] World Bank, "World Bank Development Indicators," World Bank, 2012.

http://www.google.com.pk/publicdata/explore?ds=d5bncp pjof8f9_\&met_y=it_net_user_p2\&idim=country:PAK\&dl $=$ en $\& \mathrm{hl}=$ en $\& \mathrm{q}=$ internet + users + in + Europe

[10] K. A. Armstrong, "Principles of Marketing," 13th Edition, Pearson, Newyork, 2010.

[11] S. B. Gerald Lohse, "Consumer Buying Behavior on the Internet: Findings from Panel Data," Journal of Interactive Marketing, Vol. 14, No. 1, 2000, p. 15.

[12] T. Ravikumar, "A Study on Impact of Visual Media Advertisements on Women Consumers Buying Behaviour in Chennai City," International Journal of Multidisciplinary Research, Vol. 2, No. 2, 2012, pp. 78-89.

[13] P. Manchanda, "The Effect of Banner Advertising on Internet Purchasing," American Marketing Association, Vol. 43, No. 1, 2006, pp. 98-108.

[14] “In today's Paper," The Wall Street Journal, B7, 27 July 2004.

[15] G. Lohse, "Consumer Buying Behaviour on the Internet: Findings from Panel Data," Journal of Interactive Marketing, Vol. 14, No. 1, 2000, p. 15. http://dx.doi.org/10.1002/(SICI)1520-6653(200024)14:1< 15::AID-DIR2>3.0.CO;2-C

[16] Grab Stats, "Grab Stats Stat Category Main," Grab Stats, 2012. http://grabstats.com/statmain.asp?StatID=1

[17] T. P. Tse, "A Hedonic Model for Effective Web Marketing: An Empirical Examination," Industrial Management and Data System, Vol. 105, No. 8, 2005, pp. 1039-1052.

[18] E. J. Rutgars, "Antecedents and Consequences of Emotional Responses to Advertising," Advances in Consumer Research, Vol. 30, No. 1, 2003, pp. 85-90.

[19] G. Rosenkrans, "The Creativeness and Effectiveness of Online Interactive Rich Media Advertising," Journal of Interactive Advertising, Vol. 9, No. 2, 2007, pp. 259-267.

[20] C. K. Yoo, "Assessing the Effects of Animation in Online Banner Advertising," Hierarchy of Effects Model, Journal of Interactive Advertising, Vol. 4, No. 2, 2004, pp. 45-58. http://dx.doi.org/10.1080/15252019.2004.10722087

[21] P. B. Wise, "Enjoyment of Advergames and Brand Atti- 
tudes," The Impact of Thematic Relevance, Journal of Interactive Advertising, Vol. 9, No. 1, 2008, pp. 27-36. http://dx.doi.org/10.1080/15252019.2008.10722145

[22] N. T. Loiacono, "Alternatives Scenarios to the Banner Years," Communication of the Associations of the Computing Machinery (ACM), Vol. 51, No. 2, 2008, pp 53-58.

[23] A. Kumar, "Term Paper: Online Advertisement," Hochschle Furtwangen University, 2008.

[24] G. V. Häubl, "Consumer Decision Making in Online Shopping Environments," The Effects of Interactive Decision Aids, Vol. 19, No. 1, 2000, pp. 4-21.

[25] R. L. Andrews, "Behavioral Differences," Working Paper, 2000.

[26] N. V. Bakos, "Bundling and Competition on the Internet," Marketing Science, Vol. 19, No. 1, 2000, pp. 63-82. http://dx.doi.org/10.1287/mksc.19.1.63.15182

[27] Ronald and Barbara, "Consumer Response to Web Sites and Their Influence on Advertising Effectiveness," Internet Research, Vol. 12, No. 4, 2002, pp. 318-328.

[28] Bibliography\1 1033 ADEX, "European Online Advertising Expenditure," IAB Europe, 2001.

[29] ADEX, "European Online Advertising Expenditure," IAB Europe, 2002.

[30] ADEX, "European Online Advertising Expenditure," IAB Europe, 2003.

[31] ADEX, "European Online Advertising Expenditure," IAB Europe, 2004.
[32] ADEX, "European Online Advertising Expenditure," IAB Europe, 2005.

[33] ADEX, "European Online Advertising Expenditure," IAB Europe, 2006.

[34] ADEX, "European Online Advertising Expenditure," IAB Europe, 2007.

[35] ADEX, "European Online Advertising Expenditure," IAB Europe, 2008.

[36] ADEX, "European Online Advertising Expenditure," IAB Europe, 2009.

[37] G. Jeffrey, "Europe Retail E-Commerce," E-Marketer, New York, 2010

[38] Zenithoptimedia, "Advertising Expenditure Forecasts," 2011.

[39] J. N. Eric, "Banner Advertisement and Web Site Congruity Effects on Consumer Web Site Perceptions," Industrial Management \& Data Systems, Vol. 104, No. 3, 2004, pp. 273-281.

[40] E. G. Ronald, "Consumer Response to Web Sites and Their Influence on Advertising Effectiveness," Internet Research, Vol. 12, No. 4, 2002, pp. 318-328.

[41] K. K. Wei, et al., "Online Advertising: A Study of Malaysian Consumers," International Journal of Business and Information, Vol. 5, No. 2, 2010. 